\title{
Reintervention for endograft failures after thoracic endovascular aortic repair
}

\author{
Wilson Y. Szeto, MD, ${ }^{a}$ Nimesh D. Desai, MD, PhD, ${ }^{a}$ Patrick Moeller, BS, ${ }^{a}$ G. William Moser, CRNP, ${ }^{\mathrm{a}}$ \\ Edward Y. Woo, MD, ${ }^{\mathrm{b}}$ Ronald M. Fairman, MD, ${ }^{\mathrm{b}}$ Alberto Pochettino, MD, ${ }^{\mathrm{a}}$ and Joseph E. Bavaria, MD ${ }^{\mathrm{a}}$
}

Objective: Thoracic endovascular aortic repair has emerged as an effective therapy for a variety of thoracic aortic pathologic entities. However, endograft failure remains a concern, and its treatment is often challenging. We examined our experience with endograft failure and its treatment by endovascular and open repair.

Methods: From January 2000 to January 2012, 680 patients underwent thoracic endovascular aortic repair at the University of Pennsylvania, and their charts were reviewed for the late outcomes and follow-up data.

Results: Of the 680 patients, 73 underwent 80 reinterventions (11.7\%) during follow-up. The indications for index thoracic endovascular aortic repair were thoracic aortic aneurysms in 381, type A dissection with frozen elephant trunk in 52, type B dissection in 111, hybrid arch repair in 46, traumatic transection in 37, infection in 10 , penetrating atherosclerotic ulcer in 25 , and others in 18 . The median interval from index thoracic endovascular aortic repair to reintervention was 210 days. Endograft failures included endoleak in 45, proximal aortic events in 11, distal aortic events in 15, endograft infection in 3, and others in 6 . Endovascular reintervention $(\mathrm{n}=80)$ was performed in 60 patients. In 20 patients, open aortic reconstructive procedures were performed. The overall 30-day mortality was 8.7\% (7/80). During follow-up, 10 late deaths occurred. The overall survival in all patients was $81 \%, 60 \%$, and $52 \%$ at 1,5 , and 7 years, respectively. The late survival for patients after reintervention for endograft failure was similar that for the patients who did not require reintervention $(P=.31)$.

Conclusions: Reintervention for endograft failure can be performed with acceptable early outcomes. The midterm survival for patients requiring reintervention for endograft failure was similar to that of the patients without endograft failure. Thus, reintervention for endograft failure should be aggressively considered when indicated. (J Thorac Cardiovasc Surg 2013;145:S165-70)

Since its introduction in the 1990s, thoracic endovascular aortic repair (TEVAR) has emerged as an alternative surgical therapy for thoracic aortic pathologic entities. ${ }^{1-4}$ However, the long-term results have remained limited, and the durability of TEVAR continues to be a concern. ${ }^{5}$ Furthermore, the application of endograft technology has expanded to include "off-label" indications, such as aneurysmal disease with marginal anatomy and landing zones, aortic dissections, arch hybrid procedures, traumatic transection, and infection.

Endograft failure has remained a significant clinical concern. The failure modes of TEVAR include endoleak, stent fracture and migration, proximal and distal aortic degenerative events, and infection. ${ }^{6}$ Endovascular or surgical

\footnotetext{
From the Division of Cardiovascular Surgery ${ }^{\mathrm{a}}$ and Division of Vascular and Endovascular Surgery ${ }^{\mathrm{b}}$, University of Pennsylvania Medical Center, Philadelphia, Pa.

Disclosures: Drs Szeto, Desai, Moeller, Moser, Woo, Fairman, Pochettino, and Bavaria have nothing to disclose with regard to commercial support.

Presented at the American Association for Thoracic Surgery Aortic Surgery Symposium 2012, April 26-27, 2012, New York, NY.

Received for publication April 26, 2012; revisions received Oct 11, 2012; accepted for publication Nov 20, 2012.

Address for reprints: Wilson Y. Szeto, MD, Division of Cardiovascular Surgery, Penn Presbyterian Medical Center, University of Pennsylvania Medical Center, $51 \mathrm{~N}$ 39th St, PHI Suite 2A, Philadelphia, PA 19104 (E-mail: Wilson.szeto@uphs. upenn.edu).

0022-5223/\$36.00

Copyright (c) 2013 by The American Association for Thoracic Surgery

http://dx.doi.org/10.1016/j.jtcvs.2012.11.046
}

reintervention in these high-risk patients has been demonstrated to be associated with significant morbidities and mortality. ${ }^{7-13}$ We report our experience with endograft failure and the results of our endovascular and surgical reintervention in 680 patients during the past decade.

\section{METHODS}

We performed a retrospective review of the thoracic aortic surgery clinical database at the University of Pennsylvania from January 2000 to January 2012. The University of Pennsylvania TEVAR registry is a prospectively maintained perioperative database of thoracic aortic endograft procedures. Electronic and paper charts were reviewed for preoperative patient and demographic characteristics, the clinical presentation, the indication for surgery, perioperative events and complications, and mortality. Postoperative and late clinical outcomes were obtained from lifelong, continual follow-up data and patient surveillance from the Penn Thoracic Aortic Surgery clinic.

From January 2000 to January 2012, a total of 680 patients underwent TEVAR at the University of Pennsylvania. Of these 680 patients, 73 patients underwent 80 endovascular and surgical reinterventions for endograft failure during follow-up. An additional 5 patients underwent reintervention for endograft failure. However, the index TEVAR procedures had been performed at a different outside institution. These 5 patients were excluded from the present study because of uncertainties regarding their preoperative clinical history and the scenario of the index TEVAR.

\section{Statistical Analysis}

All continuous variables are expressed as the mean \pm standard deviation. Univariate analysis was performed with Fisher's exact test to compare 


\section{Abbreviation and Acronym \\ TEVAR $=$ thoracic endovascular aortic repair}

categorical variables and Student's $t$ test to compare continuous variables. Statistical methods were applied to compare the freedom from reintervention and late survival using Kaplan-Meier curves. Late survival data were determined using a linkage to the national Social Security Death Index. Probability values for long-term survival were calculated using the logrank test. SPSS software, version 19.0 (SPSS, Inc, Chicago, Ill) was used for all calculations. The institutional review board at the University of Pennsylvania approved the study and waived the need for patient consent.

\section{RESULTS}

\section{Indications for Index TEVAR}

The preoperative patient characteristics and indications for index TEVAR are listed in Table 1 . The mean patient age at the index TEVAR was $68 \pm 13$ years and at reintervention was $69 \pm 13$ years. A total of 680 patients underwent TEVAR for a variety of thoracic aortic pathologic entities. The index procedures and indications for TEVAR included endograft repair for descending thoracic aortic aneurysm in 381, proximal repair with frozen elephant trunk for acute type A aortic dissection in 52; endograft repair for acute and chronic type B aortic dissection in 77 and 34 , respectively, endograft repair for traumatic transection in 37; arch hybrid repair for extended aneurysm disease of the arch and thoracic aorta in 46, endograft repair for infected aortic pathologic features in 10, penetrating atherosclerotic ulcer in 25 , and others in 18 . In the 10 patients with infected aortic pathologic features as the indication for the index TEVAR, mycotic aneurysm was seen in 4 patients, aortoesophageal fistula in 2 , aortobronchial fistula in 3 , and an infected aortic homograft in 1 patient.

\section{Reintervention and Early Outcomes}

Of the 680 patients treated with TEVAR, 73 patients underwent 80 reinterventions $(80 / 680,11.7 \%$ ). In 7 patients, 2 separate reintervention events were required. The modes of endograft failure are listed in Table 1 . The most common mode of endograft failure was endoleak $(n=45,56 \%)$. The median interval from the index TEVAR to reintervention was 210 days. The rates of reintervention according to the indication for the index TEVAR are listed in Table 2. Endovascular repair was undertaken in 60 patients and open surgical repair in 20. In the 60 patients who underwent endovascular repair, the procedures included additional TEVAR in 50 patients, placement of a bare metal PALMAZ stent (Cordis Corp, Miami Lakes, Fla) in the proximal landing zone for endoleak in 1 patient, an arch chimney endograft technique for proximal endoleak in 1 patient (Figure 1), a distal chimney endograft technique to the superior mesenteric artery and right renal artery for distal endoleak in 1
TABLE 1. Preoperative patient demographics

\begin{tabular}{lc}
\hline \multicolumn{1}{c}{ Patient demographics } & Value \\
\hline At index TEVAR & \\
Age (y) & $68 \pm 13$ \\
Aortic pathologic features & 680 \\
Descending thoracic aortic aneurysm & $381(56 \%)$ \\
Type A dissection repair with FET & $52(8 \%)$ \\
Acute type B dissection & $77(11 \%)$ \\
Chronic type B dissection & $34(5 \%)$ \\
Arch hybrid repairs & $46(7 \%)$ \\
Traumatic transection & $37(5 \%)$ \\
Infection (mycotic, A-B-E fistula) & $10(1 \%)$ \\
Penetrating atherosclerotic ulcers & $25(4 \%)$ \\
Other & $18(3 \%)$ \\
At reintervention & \\
Age (y) & $69 \pm 13$ \\
Modes of failure & \\
Endoleak & $45(56 \%)$ \\
Type I & 24 \\
Type II & 5 \\
Type III & 9 \\
Multiple or unclear origin & 7 \\
Proximal aortic events & $11(14 \%)$ \\
Retrograde type A dissection & 9 \\
Aneurysmal degeneration & 2 \\
Distal aortic events (dissection/expansion) & $15(18 \%)$ \\
Multiple failure modes & $4(5 \%)$ \\
Endograft infection & $3(4 \%)$ \\
Other (carotid occlusion, stent collapse) & $2(3 \%)$ \\
\hline$T E V A R$, Thoracic endovascular aortic repair; FET, frozen & \\
$A-B-E$ fistula, aortobronchial, aortoesophageal fistula. & trunk; \\
&
\end{tabular}

patient, concomitant TEVAR/endovascular aortic repair for aneurysmal degeneration in 1 patient, branch artery coil embolization for type II endoleak in 3 patients, proximal reballooning of an existing endograft for endoleak in 2 patients, and deployment of an Amplatz device in the left subclavian artery for type II endoleak in 1 patient. In the 20 patients who underwent open reintervention, the procedures included repair of retrograde type A aortic dissection in 9 patients, arch debranching with new adjunct TEVAR for endoleak in 1 patient, bypass of a partially covered left common carotid to ascending aorta after maldeployment of TEVAR in 1 patient, open total arch reconstruction for type I endoleak in 1 patient, abdominal visceral debranching for distal endoleak and aneurysmal degeneration in 2 patients, and distal repair of thoracoabdominal aortic aneurysm, with in 4 patients and without in 2 patients, explantation of the previous endograft (Figure 2). The overall 30-day mortality was $8.7 \%$ (7/80). The 30-day mortality according to the mode of endograft failure is listed in Table 3. The postoperative 30-day complications are listed in Table 4 . The 30-day mortality for endovascular and open reintervention was similar at $6.7 \%$ and $15 \%$, respectively $(P=.35)$. The causes of death are listed in Table 5. 
TABLE 2. Indication for index TEVAR and reintervention rate

\begin{tabular}{lc}
\hline Index pathologic indication for TEVAR & Reintervention rate (\%) \\
\hline All causes & $80 / 680(11.7 \%)$ \\
Descending thoracic aneurysm & $46 / 381(12 \%)$ \\
Type A dissection & $13 / 52(25 \%)$ \\
Acute type B dissection & $11 / 77(14 \%)$ \\
Chronic type B dissection & $4 / 34(12 \%)$ \\
Arch hybrid & $1 / 46(2 \%)$ \\
Traumatic transaction & $2 / 37(5 \%)$ \\
Infection (mycotic, A-B-E fistula) & $2 / 10(20 \%)$ \\
PAU & $0 / 25(0 \%)$ \\
Other & $1 / 18(6 \%)$
\end{tabular}

$\overline{T E V A R}$, Thoracic endovascular aortic repair; $A-B-E$ fistula, aortobronchial, aortoesophageal fistula; $P A U$, penetrating atherosclerotic ulcer.

\section{Late Outcomes}

During follow-up, the overall survival for the entire group (all patients who underwent TEVAR) was $81 \%, 69 \%$, $60 \%$, and $52 \%$ at $1,3,5$, and 7 years, respectively. In the entire cohort of 680 patients, the freedom from reintervention after TEVAR was $92 \%, 88 \%$, and $86 \%$ at 1,3 , and 5 years, respectively. In the 73 patients who underwent 80 reinterventions for endograft failure, 10 late deaths occurred. The cause of late death was aorta related in 1 patient (bleeding complications after visceral debranching), nonaorta related in 4 patients, and unknown in 5 patients. The late survival for the patients after reintervention for endograft failure was similar to that for those who did not require reintervention for endograft failure $(P=.11$; Figure 3$)$.

\section{DISCUSSION}

Because large series of TEVAR with long-term follow-up are limited, the determination of the true incidence of endograft failure and the rate of reintervention remains challenging. Early experience has suggested that reintervention is rare. ${ }^{8-12,14}$ However, accumulating data have suggested that endograft failure is a significant concern and that reintervention might occur at a greater frequency than anticipated. $^{7,13}$ In reviewing our experience with 680 patients who underwent TEVAR during the past decade, the rate of reintervention for endograft failure was $11.7 \%$.

The cause of endograft failure was multifactorial and likely a reflection of suboptimal patient selection, questionable indications for TEVAR, and marginal anatomic and aortic landing zones. Since the approval of the TEVAR device for aneurysmal disease in 2005 , the application of this new technology for expanded indications - including nonaneurysmal pathologic features-has gained widespread adoption. In some series examining patients requiring late reintervention, the rate of "off-label" use of endografts was as great as 70\% for the index TEVAR. ${ }^{7}$ In our series, $44 \%$ of patients were treated with TEVAR for nonaneurysmal pathologic features. These indications included aortic dissection, traumatic transection, infected aortic pathologic features, hybrid arch repair, penetrating atherosclerotic ulcer, and others.

The initial indication for TEVAR is likely a major contributing factor in predicting endograft failure, and our data certainly suggest this. Of the 80 reinterventions for endograft failure, 34 reinterventions were performed in patients whose indication for index TEVAR was nonaneurysmal descending thoracic aortic pathologic features. An interesting group is the patients undergoing type A aortic dissection with frozen elephant trunk in an attempt to alter distal aortic remodeling: 13 reinterventions in 52 patients $(25 \%)$ were performed after initial repair because of suboptimal distal aortic remodeling and persistent false lumen patency in the stented portion of the thoracic aorta. Our early experience has demonstrated evidence of positive distal aortic remodeling in most patients treated with the frozen elephant trunk. False lumen obliteration in the stented portion of the thoracic aorta occurs in $80 \%$ of patients, with complete thoracoabdominal false lumen thrombosis in $17 \% .^{2}$ Other groups have reported similar early results. ${ }^{15,16}$ However, the incidence of reintervention remains relatively high, and the benefit of these
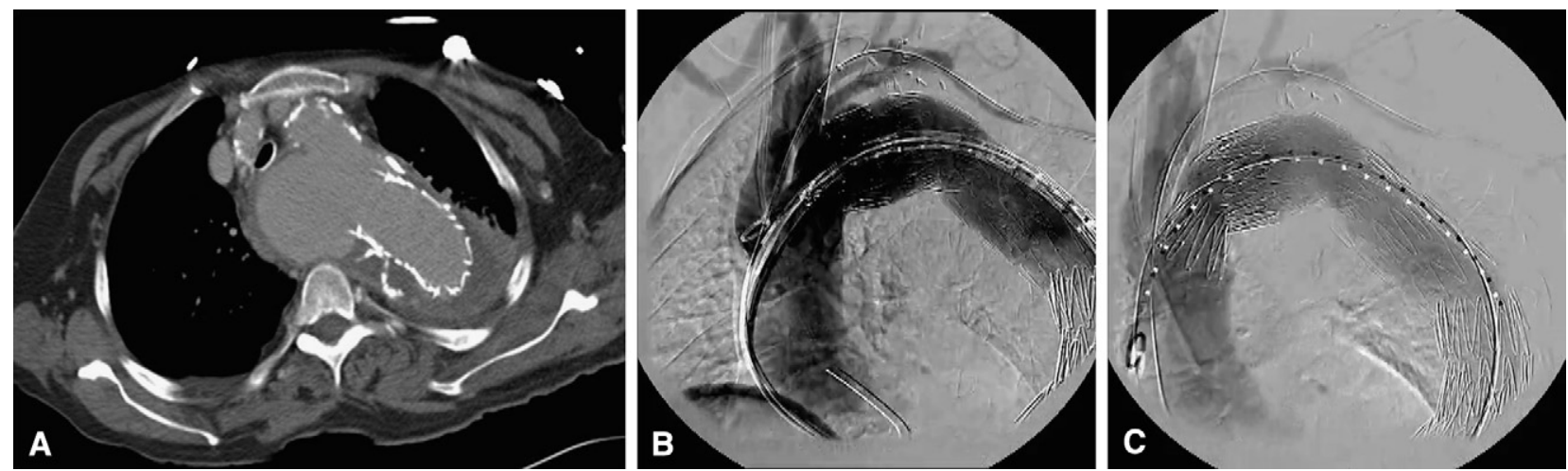

FIGURE 1. Reintervention using arch chimney technique for proximal endoleak. A, Computed tomography scan of proximal endoleak after previous thoracic endovascular aortic repair. B, Intraoperative aortogram of proximal endoleak after previous thoracic endovascular aortic repair. C, Intraoperative aortogram of proximal extension with adjunct thoracic endovascular aortic repair and left common carotid artery stent placement (arch chimney technique). 

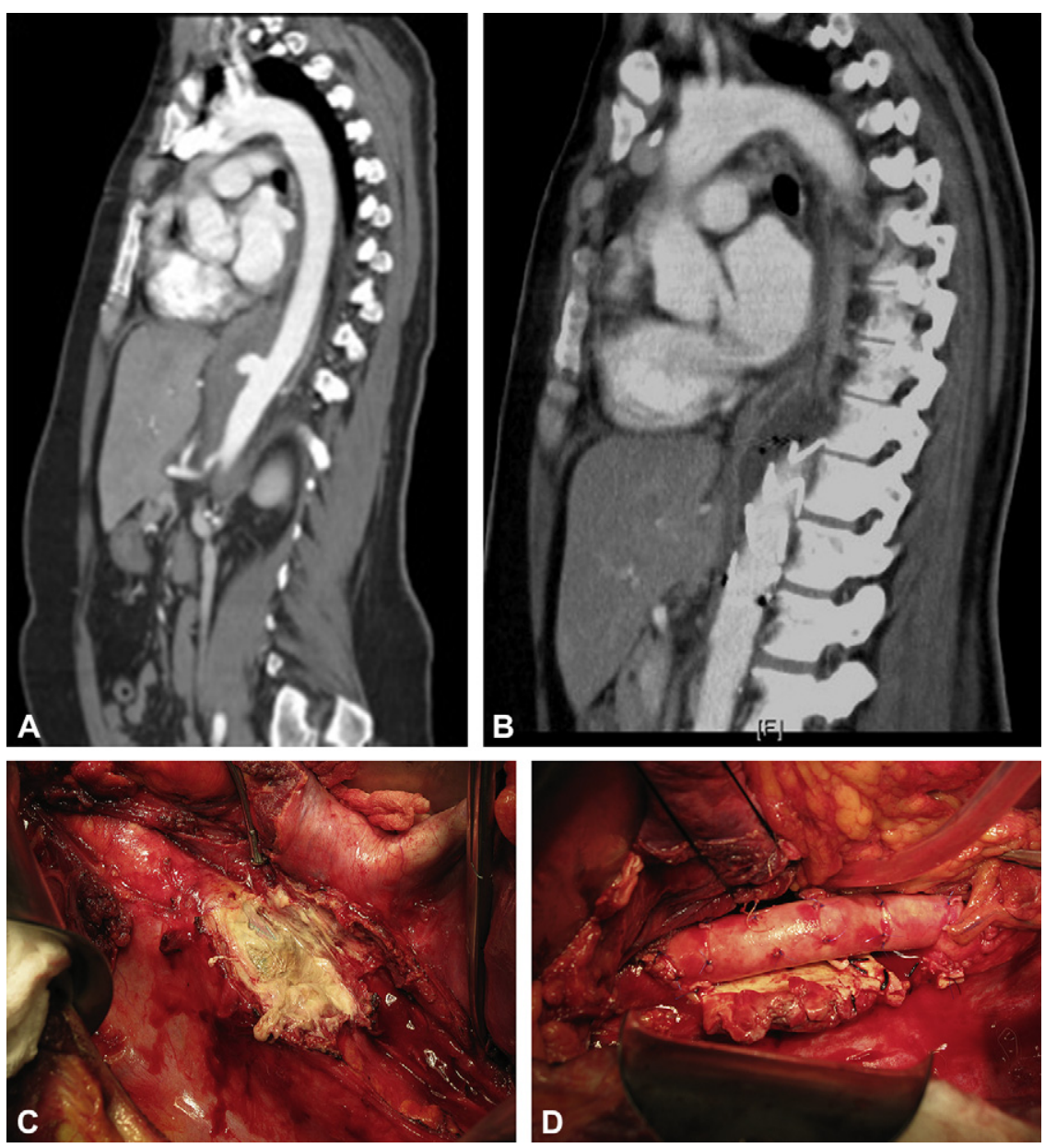

FIGURE 2. Open conversion for infected endograft. Computed tomography scan demonstrating infected endograft with A, pseudoaneurysm with B, peri-graft air. C, Infected thoracic aortic endograft. D, Explantation and reconstruction using aortic homograft.

reinterventions remains in question. The concept of positive distal aortic remodeling as a result of concomitant TEVAR in the distal thoracoabdominal aorta remains to be investigated, and long-term follow-up data are needed before definitive conclusions can be drawn., ${ }^{2,20}$

Another interesting and difficult group to manage is patients with infected aortic pathologic entities and endograft infection. The reintervention and complication rates in this group of patients were also relatively high. Our significant

TABLE 3. Mode of failure and reintervention 30-day mortality

\begin{tabular}{lc}
\hline \multicolumn{1}{c}{ Failure mode } & 30-d Mortality (\%) \\
\hline Total & $7 / 80(8.7 \%)$ \\
Endoleak & $2 / 45(4.4 \%)$ \\
Proximal aortic events (retrograde type A, & $2 / 11(18 \%)$ \\
$\quad$ aneurysmal degeneration) & \\
Distal aortic events (dissection, aneurysmal & $1 / 15(6.7 \%)$ \\
$\quad$ degeneration) & \\
Multiple failure modes (excluding infection) & $0 / 4(0 \%)$ \\
Endograft infection & $1 / 3(33 \%)$ \\
Other (carotid occlusion, stent collapse) & $1 / 2(50 \%)$ \\
\hline
\end{tabular}

morbidity and mortality in this group of patients mirrors the experience from other centers. ${ }^{11}$ In the 10 patients with infected aortic pathologic features as the index

TABLE 4. Complications at 30 days: open versus endovascular reintervention

\begin{tabular}{|c|c|c|c|c|}
\hline Complication & $\begin{array}{c}\text { Total } \\
(\mathbf{n}=\mathbf{8 0})\end{array}$ & $\begin{array}{c}\text { Open } \\
(\mathbf{n}=\mathbf{2 0})\end{array}$ & $\begin{array}{c}\text { Endovascular } \\
\quad(\mathbf{n}=60)\end{array}$ & $\begin{array}{c}P \\
\text { value* }\end{array}$ \\
\hline 30-d Mortality & $7(8.7 \%)$ & $3(15 \%)$ & $4(6.7 \%)$ & .35 \\
\hline Reoperation for bleeding & $2(2.5 \%)$ & $1(5 \%)$ & $1(1.7 \%)$ & .43 \\
\hline $\begin{array}{l}\text { Permanent paraplegia/ } \\
\text { paraparesis }\end{array}$ & $0(0 \%)$ & $0(0 \%)$ & $0(0 \%)$ & \\
\hline $\begin{array}{l}\text { Temporary paraplegia/ } \\
\text { paraparesis }\end{array}$ & $2(2.5 \%)$ & $0(0 \%)$ & $2(3.3 \%)$ & 1 \\
\hline Stroke & $1(1.3 \%)$ & $0(0 \%)$ & $1(1.7 \%)$ & 1 \\
\hline Renal failure & $7(8.7 \%)$ & $3(15 \%)$ & $4(6.7 \%)$ & .35 \\
\hline $\begin{array}{l}\text { Renal failure requiring } \\
\text { dialysis }\end{array}$ & $4(5 \%)$ & $3(15 \%)$ & $1(1.7 \%)$ & .04 \\
\hline Ventilation $>24 \mathrm{~h}$ & $13(16 \%)$ & $4(20 \%)$ & $9(15 \%)$ & .72 \\
\hline Length of stay (d) & $12.2 \pm 13$ & $20.1 \pm 19.7$ & $9.4 \pm 8.8$ & .02 \\
\hline
\end{tabular}


TABLE 5. Reintervention and cause of death

\begin{tabular}{lllll}
\hline Pt. No. & Indication for index TEVAR & \multicolumn{1}{c}{ Failure mode } & \multicolumn{1}{c}{ Reintervention } & \multicolumn{1}{c}{ Cause of death } \\
\hline 1 & DTA & Distal aneurysmal degeneration & TEVAR/chimney to SMA/renal & Mesenteric ischemia \\
2 & DTA & Type I endoleak & TEVAR & Rupture \\
3 & Traumatic Transection & Carotid occlusion & Open ascending to carotid bypass & MSOF \\
4 & DTA & Retrograde type A dissection & Open proximal repair with hemiarch & Bleeding/biventricular failure \\
5 & DTA & Retrograde type A dissection & Open proximal repair with hemiarch & MSOF \\
6 & DTA & Endoleak type III & TEVAR & Rupture \\
7 & DTA & Endoleak/infection & TEVAR & Sepsis \\
\hline
\end{tabular}

Pt. No., Patient number; TEVAR, thoracic endovascular aortic repair; DTA, descending thoracic aortic aneurysm; SMA, superior mesenteric artery; MSOF, multisystem organ failure.

indication for TEVAR, 2 patients underwent no additional reintervention but both succumbed to their initial infectious etiology and developed late rupture due to ongoing infection of the endograft at 3 months. Of the remaining 8 patients, 3 underwent open explantation for infection recurrence, with an operative mortality of $33 \%$. Infection recurrence or death occurred in 5 of 10 patients $(50 \%)$. Infections such as mycotic aneurysm, aortobronchial fistula, and aortoesophageal fistula are at high risk of late endograft failure; they reflect the surgical principle that prohibits placement of synthetic graft material in an infected field. Owing to our early dismal results with cases involving infection, our new paradigm at our institution is to use TEVAR as bridging therapy in a planned 2-stage approach. Emergent TEVAR for patient stabilization is performed to mitigate the deleterious effects of sepsis and hemorrhagic shock. Once the patient's status has been medically optimized, a planned second-stage open repair with explantation of the endograft is performed, allowing more definitive open repair when the patient is stable.

The mode of failure is also likely a major contributing factor in predicting a poor clinical outcome. As discussed previously, endograft infection is associated with significant morbidity and mortality. Proximal aortic events, particularly retrograde type A aortic dissection, remain another difficult clinical scenario. Although rare in our series $(1.3 \%, 9 / 680$ patients), the mortality associated with open repair was $22 \%$ (2/9 patients). Other series have reported a similar incidence and poor outcome. ${ }^{17-19}$ Eggebrecht and colleagues ${ }^{19}$ recently reported their experience in Europe: retrograde type A dissection occurred in $1.33 \%$, with mortality of $42 \%$. The cause of retrograde type A dissection is likely multifactorial. The factors associated with its occurrence include type $\mathrm{B}$ dissection as the indication for treatment, the failure to cover the tear site during endograft treatment, aggressive oversizing, and ballooning. In using TEVAR for expanded indications, recognition of the

\section{Survival after TEVAR}

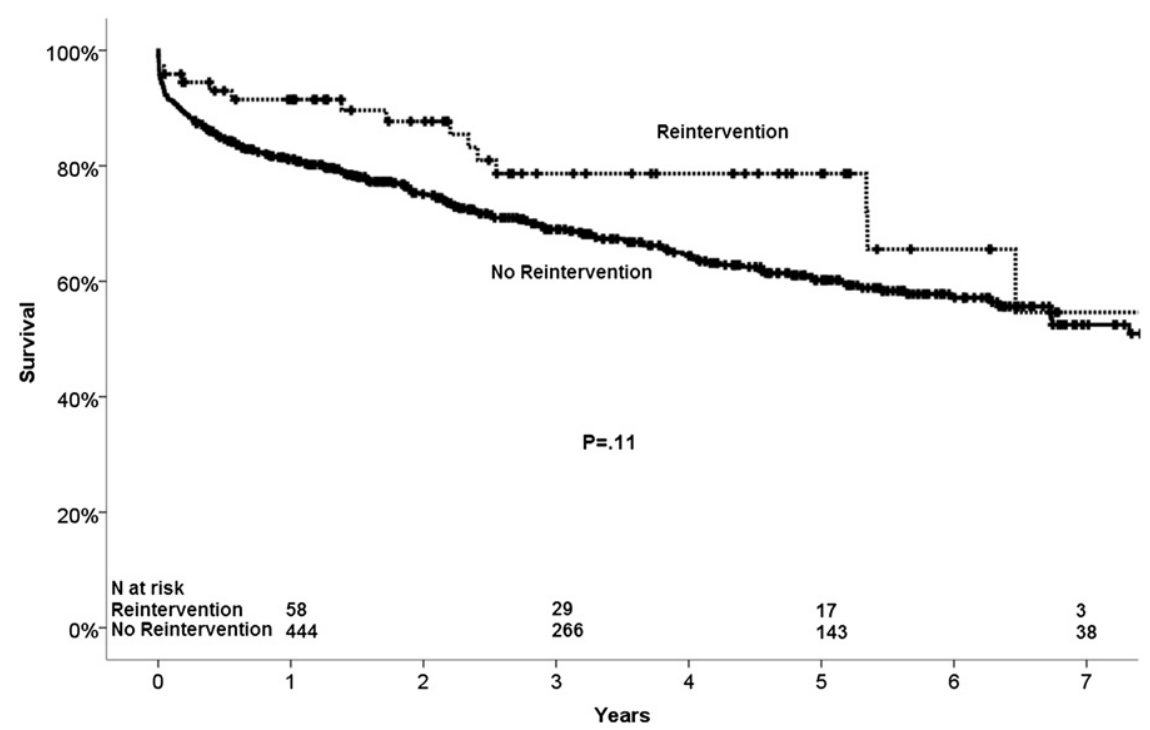

FIGURE 3. Kaplan-Meier survival curve of patients treated with thoracic endovascular aortic repair (TEVAR). Late survival in patients after reintervention for endograft failure was similar to that for patients who did not require reintervention $(P=.11)$. 
limitation of these devices must be considered and appropriate preventive steps taken.

Although the complications were significant in selected patients undergoing reintervention (the clinical scenario discussed so far), our data are nevertheless encouraging and have demonstrated that reintervention can be achieved with acceptable morbidity and mortality in most patients, despite their elderly age and comorbidities. Our overall 30-day mortality was $8.7 \%$, with the incidence of stroke, paraplegia, and renal failure at $1.3 \%, 2.5 \%$, and $8.7 \%$, respectively. Paraplegia occurred in 2 patients (both in the endovascular reintervention group). However, both patients experienced only temporary spinal cord ischemia, and their neurologic status resolved with no deficit. No instance of permanent paraplegia developed. When comparing patients who required open versus endovascular reintervention, no difference was seen in the 30-day mortality $(15 \%$ vs $6.7 \%, P=.35$ ). Open reintervention was, however, associated with a greater incidence of renal failure requiring dialysis and a prolonged length of stay. The late survival for the patients after reintervention for endograft failure was similar to the survival for patients who did not undergo reintervention (no endograft failure). Our experience supports an aggressive approach in treating endograft failure, because the perioperative mortality was relatively low and the late outcomes after reintervention were promising.

The limitation of the present study was that it was a retrospective review of the experience at a single center. Furthermore, this was a heterogeneous population of patients with different characteristics and indications for TEVAR. Furthermore, what was sobering was that the late survival, despite an aggressive approach to reintervention, hovered around $50 \%$. Our late outcomes were similar to those from other reported series, demonstrating that patients with aortic pathologic entities have significant nonaortic comorbidities that likely will limit their long-term survival.

\section{CONCLUSIONS}

TEVAR has emerged as an effective therapy for a variety of thoracic aortic pathologic entities. The incidence of late endograft failure was not insignificant, supporting the importance of lifelong aortic surveillance for all patients who have undergone TEVAR. Suboptimal patient selection, the particular indications for treatment, and certain aortic anatomic characteristics are factors contributing to endograft failure. However, reintervention for endograft failure can be achieved with acceptable early and late outcomes. Just as at other centers, our center has adopted endovascular technology with great enthusiasm, especially for patients whom we believe are at extreme risk of conventional open surgery. However, an awareness and recognition of the limitations of the current technology must be present, and a balance struck between overly enthusiastic embrace and prudent application with realistic expectations.

\section{References}

1. Makaroun MS, Dillavou ED, Wheatley GH, Cambria RP, Gore TAG investigators. Five-year results of endovascular treatment with Gore TAG device compared with open repair of thoracic aortic aneurysms. J Vasc Surg. 2008;47:912-8.

2. Pochettino A, Brinkman WT, Moeller P, Szeto WY, Moser W, Cornelius K, et al. Antegrade thoracic stent grafting during repair of acute DeBakey I dissection prevents development of thoracoabdominal aortic aneurysms. Ann Thorac Surg. 2009;88:482-90

3. Szeto WY, McGarvey M, Pochettino A, Moser GW, Hoboken A, Cornelius K, et al. Results of a new surgical paradigm: endovascular repair for acute complicated type B aortic dissection. Ann Thorac Surg. 2008;86:87-94.

4. Milewski RK, Szeto WY, Desai ND, Moser GW, Moeller P, Bavaria JE. Have hybrid procedures replaced open aortic arch reconstruction in high risk patients: a comparative study of open arch debranching with endovascular stent graft placement and conventional open total and distal aortic arch reconstruction. J Thorac Cardiovasc Surg. 2010;90:1230-5.

5. Desai ND, Pochettino A, Szeto WY, Moser GW, Moeller PJ, Sodhi N, et al. Thoracic endovascular aortic repair: evolution of therapy, patterns of use and results in a 10-year experience. J Thorac Cardiovasc Surg. 2011;142:587-94.

6. Lee WA. Failure modes of thoracic endografts: prevention and management. J Vasc Surg. 2009;49:792-9.

7. LeMaire SA, Green SY, Kim JH, Sameri A, Parenti JL, Lin PH, et al. Thoracic or thoracoabdominal approaches to endovascular device removal and open aortic repair. Ann Thorac Surg. 2012;93:726-33.

8. Canaud L, Alric P, Gandet T, Albat B, Marty-Ané C, Berthet JP, et al. Surgical conversion after thoracic endovascular aortic repair. J Thorac Cardiovasc Surg. 2011;142:1027-31.

9. Girdauskas E, Falk V, Kuntze T, Borger MA, Schmidt A, Scheinert D, et al. Secondary surgical procedures after endovascular stent grafting of the thoracic aorta: successful approaches to a challenging clinical problem. J Thorac Cardiovasc Surg. 2008;136:1289-94.

10. Dumfarth J, Michel M, Schmidli J, Sodeck G, Ehrlich M, Grimm M, et al. Mechanisms of failure and outcome of secondary surgical interventions after thoracic endovascular aortic repair (TEVAR). Ann Thorac Surg. 2011;91:1141-6.

11. Chiesa R, Tshomba Y, Kahlberg A, Marone EM, Civilini E, Coppi G, et al. Management of thoracic endograft infection. J Cardiovasc Surg. 2010;51:15-31.

12. Ehrlich MP, Nienaber CA, Rousseau H, Beregi JP, Piquet P, Schepens M, et al. Short-term conversion to open surgery after endovascular stent-grafting of the thoracic aorta: the Talent Thoracic Registry. J Thorac Cardiovasc Surg. 2008; 135:1322-6.

13. Geisbusch P, Hoffmann S, Kotelis D, Able T, Hyhlik-Dürr A, Böckler D. Reinterventions during midterm follow-up after endovascular treatment of aortic disease. J Vasc Surg. 2011;53:1528-33.

14. Kirkwood ML, Pochettino A, Fairman RM, Jackson BM, Woo EY, Wang GJ. Thoracic aortic endograft explants: a single-center experience. Vasc Endovascular Surg. 2010;44:440-5.

15. Uchida N, Katayama A, Tamura K, Sutoh M, Kuraoka M, Ishihara H. Frozen elephant trunk technique and partial remodeling for acute type A aortic dissection. Eur J Cardiothorac Surg. 2011;40:1066-71.

16. Jakob H, Tsagakis K, Tossios P, Massoudy P, Thielmann M, Buck T, et al. Combining classic surgery with descending stent grafting for acute DeBakey type I dissection. Ann Thorac Surg. 2008;86:95-101.

17. Dong ZH, Fu WG, Wang YQ, Guo da Q, Xu X, Ji Y, et al. Retrograde type A aortic dissection after endovascular stent graft placement for treatment of type B dissection. Circulation. 2009;119:735-41.

18. Ehrlich MP, Rousseau H, Heijmen R, Piquet P, Beregi JP, Nienaber CA, et al. Midterm results after endovascular treatment of acute complicated type B aortic dissection: the Talent Thoracic Registry. J Thorac Cardiovasc Surg Epub 2012 Feb 11.

19. Eggebrecht H, Thompson M, Rousseau H, Czerny M, Lönn L, Mehta RH, et al. Retrograde ascending aortic dissection during or after thoracic aortic stent graft placement: insight from the European registry on endovascular aortic repair complications. Circulation. 2009;120(11 suppl):S276-81.

20. Gorlitzer M, Weiss G, Meinhart J, Waldenberger F, Thalmann M, Folkmann S, et al. Fate of the false lumen after combined surgical and endovascular repair treating Stanford type A aortic dissections. Ann Thorac Surg. 2010;89:794-9. 